\title{
DEVELOPMENT OF A VALID AGING PROCEDURE FOR YELLOWSTONE CUTTHROAT TROUT
}

Wayne A. Hubert

\author{
Wyoming Cooperative Fish and Wildlife Research Unit \\ University of wyoming \\ Laramie \\ and
}

George T. Baxter

Department of Zoology and Physiology

University of Wyoming

Laramie

\section{Objectives}

Fishery managers are often hampered in population assessment efforts by an inability to accurately age target species. This problem prevents reliable mathematical calculations on the influence of existing or proposed regulations on fish yield and population structure. Such is the case with cutthroat trout in Yellowstone Lake, Yellowstone National Park. Currently the cutthroat trout are aged using scales, but there is substantial inaccuracy in the aging, especially among older fish.

The objective of this project is to assess alternative aging structures that may produce more accurate results. Several bony structures have been shown to be superior to scales in the aging of older fish. These structures include otoliths and various fin rays. This project will compare the results of age determinations using scales to the results obtained using other skeletal structures.

\section{Methods}

A sample of 112 cutthroat trout was obtained in September 1984 through the annual experimental gillnetting conducted by the U.S. Fish and Wildlife Service on Yellowstone Lake. The sample was returned to the University of Wyoming, Laramie, Wyoming where skeletal structures to be used for aging will be prepared for aging. Preparation for aging will be by procedures described in the literature for each structure (embedding, clearing, sectioning, etc.). The skeletal structures to be examined include scales, otoliths, and fin rays.

\section{Results}

Techniques for preparing, aging and photographing scales and fin ray sections have been developed. Most of the scale and fin ray samples have been processed and are available for analysis. 
Methods for sectioning and reading otoliths are underway. Promising results indicate a rapid, easily conducted method may be developed.

Statistical comparisons of results of reading scales, otoliths, and fin ray sections by three different observers will be made in the Spring 1985.

\section{Conclusions}

No conclusions concerning the advantage of using structures other than scales have yet to be drawn 